科 学 通 报

\title{
早寒武世辛集组磷酸盐豆粒的显微结构 和成因意义
}

\author{
赵东旭 \\ (中国科学院地质研究所, 北京 100029)
}

\section{关键词磷灰石、豆粒、内核、売层、化学淀积、粘结作用}

\section{1 地质概况}

辛集组磷块岩主要展布在华北地台的南缘 ${ }^{[1]}$. 在晋南一带,辛集组由下往上依次分为五 个岩性段: 硅质岩和硅质磷块岩段, 砂、砾质豆、鳁粒磷块岩段, 石英砂岩段, 含石膏泥质白云岩 段和砂砾屑硅质白云岩段; 各段的总厚度 $20-120 \mathrm{~m}$, 主要是一套滨海相沉积 ${ }^{[2]}$. 豆、䲡粒磷块 岩段主要发育在永济、芮城一带, 厚度 0- $10 \mathrm{~m}$, 呈大小不等的透镜层状,断断续续的展布在中 条山山脊两侧. 我们曾对这种磷块岩进行过初步研究报道, 已知它由各种豆粒、䲡粒和成分非 常复杂的基质组成 ${ }^{[3]}$; 但是,对豆粒、鲵粒的显微结构特别是对豆粒壳层的显微结构却知之葚 少. 近来,我们利用扫描电镜、 $X$ 射线能谱和 $X$ 射线衍射并配合显微镜光学对豆粒特别是对其 壳层进行了较深入地观测研究. 研究结果进一步证实豆粒内核组分非常复杂; 同时第一次揭 示出豆粒壳层的显微结构, 即它是由数百层同心层状的微米级磷灰石微层组成.

\section{2 豆粒的显微结构}

豆粒由内核和同心层状壳层两部分组成.

豆粒的内核大小不等、形态不一、成分复杂. 其大小多在 $0.1 \mathrm{~mm}$ 到 $3 \mathrm{~mm}$ 之间,呈浑圆形、 卵圆形、棱角状和次棱角状等. 就不同来源或不同成因而言,其成分可分为二种: 一种是陆源 石英砂粒和硅质岩、片岩、板岩等碎屑, 它们是陆表岩石经风化、搬运进入盆地的; 另一种则源 于盆地内部, 有砂质磷块岩碎屑、豆䲡粒碎块、磷质和铁质凝块、团块等, 它们是盆内沉积物破 碎而成或磷、铁质沉积凝聚结果. 据镜下观察和 $\mathrm{X}$ 射线能谱测试可知, 内核的主要矿物有石 英、磷灰石、赤铁矿和粘土等(图 1(a)). 但是不论内核大小、形态如何和什么样的矿物组分, 其 表面都覆以或厚或薄的磷灰石壳层(图 2,4). 这表明它们都起着赖以接受磷灰石沉积的底质 作用.

豆粒外壳的结构和成分均较内核简单得多. 在低倍单偏光镜下只能看到略显纹层的磷质 外壳及其成岩挤压、变形等情况 (图 2-b); 在某些豆粒壳层中有时也可以见到含磷砂质、含碳 磷质、硅质、铁质等微层或微透镜体 ${ }^{[3]}$. 在高倍正交偏光镜下, 则可以看到由于壳内大部分微 层的磷灰石同轴排列所引起的假十字波状消光现象 (图 4). 但是在扫描电镜中则可以清晰地

1993-03-17 收稿, 1993-09-22 收修改稿.

- 国家自然科学基金资助项目. 

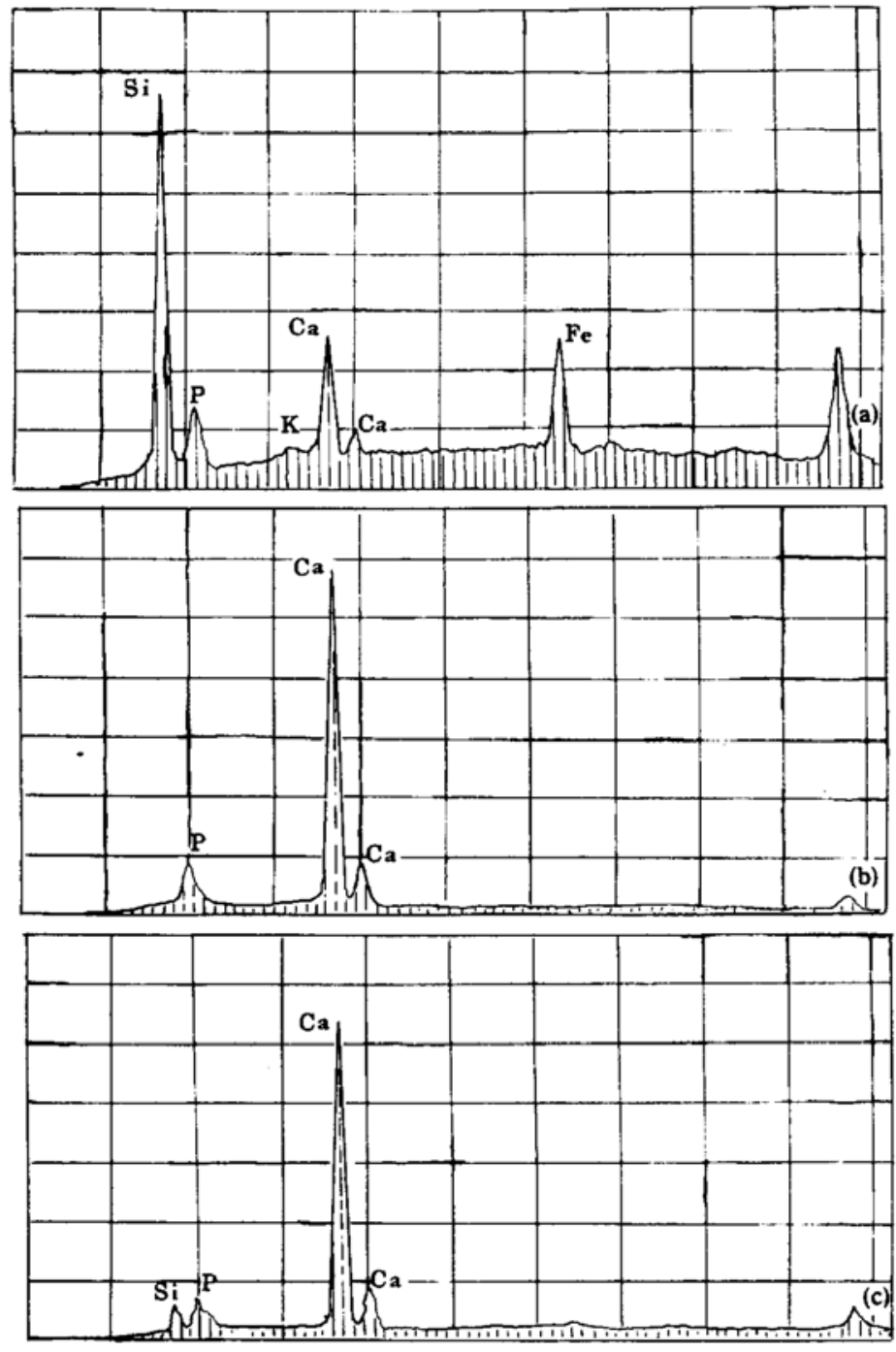

图 1 豆粒矿物的 $\mathrm{X}$ 射线能谱

(a) 豆粒内核: 石英、磷灰石、赤铁矿、粘土矿物, (b) 豆粒外壳: 磷灰石, (c) 豆粒外壳: 磷灰石, 微量石英

看到由微米级磷灰石 (图 1(b), (c)) 组成的壳层显微结构. 图 3 是豆粒壳层的一部分, 在厚约 $0.5 \mathrm{~mm}$ 的同心壳层内, 在扫描电镜中沿 A-B 方向可看到约 260 个微层, 图 5 所示微层只是其 中的一段. 如果增大观测倍数, 可以看到呈阶梯状 '叠置的微层内有两种组构不同的微层 (图 6). 第一种是具纤柱状组构的纹层. 它主要由柱状磷灰石组成. 柱状晶体的高度多小于 $1 \mu \mathrm{m}$, 并彼此平行垂直微层层面排列 (图 6-a). 这种微层的特点是每个单层的厚度都比较均匀, 覆盖 着整个豆粒表面,没有分叉和尖灭现象. 其数量在壳层中占绝对优势. 由于这种柱状磷灰石 数量上占优势并且具有垂直层面同轴排列特点, 故导致壳层的假十字波状消光 (图 4). 第二种 是具有微粒组构的微层. 这种微层是由更加微小的磷灰石颗粒组成. 在微层内, 颗粒略成层 状排列,颗粒之间有不规则状孔隙 (图 6-b). 在高倍偏光镜下可见这些磷灰石颗粒的光性方位

1) 由于电镜扫描断面与壳层内微层层面斜交所致. 


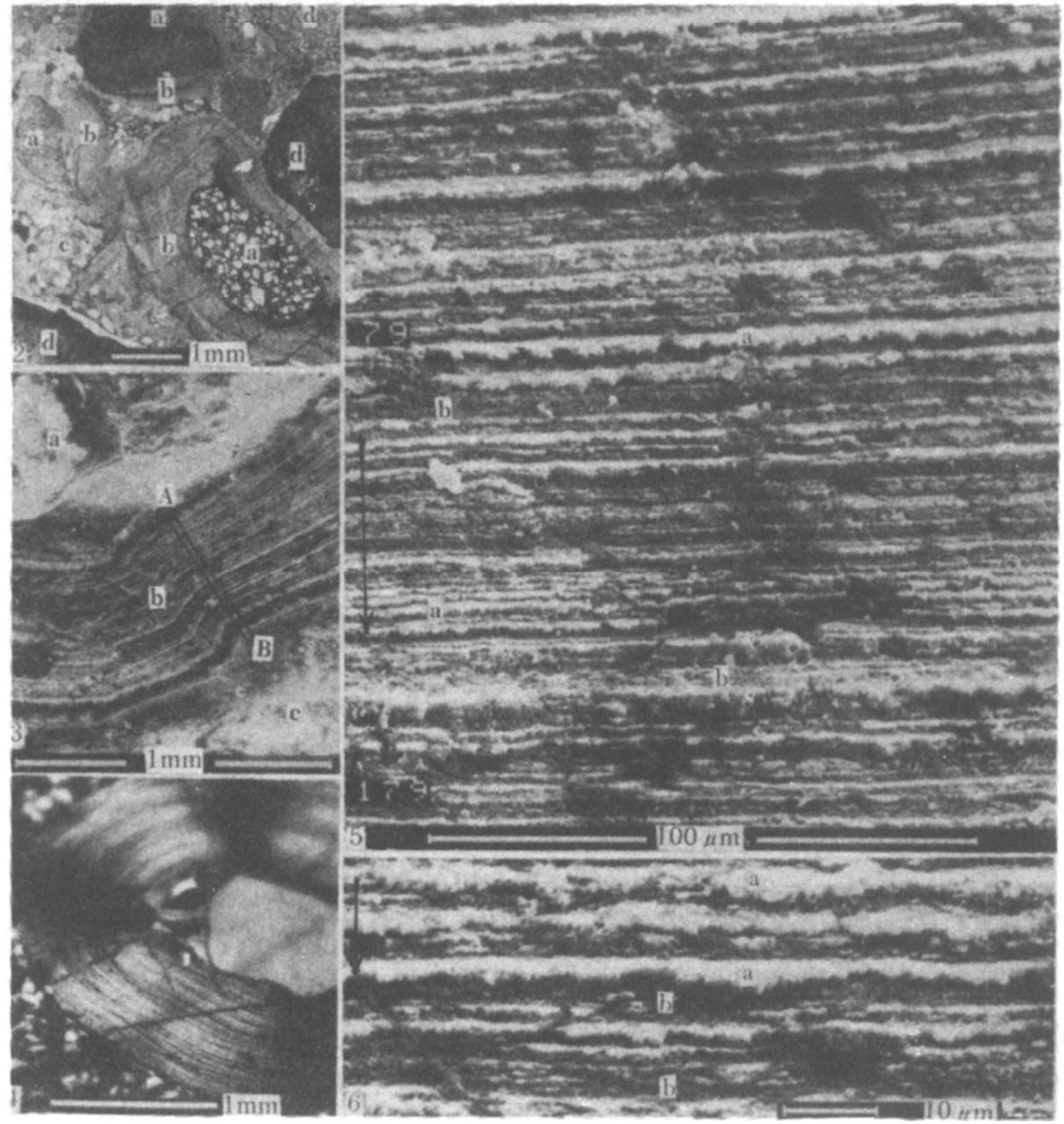

图 2-6 磷质豆粒的显微结构

2. 砾质豆粒磷块岩: 由豆粒的内核 (a)、壳层 (b) 和凝块磷灰石、石英粒 (c) 及细砾石 (d) 组成;

3. 豆粒中的部分内核 (a)、壳层 (b) 和外部的凝块状磷灰石基质 (c), A-B 为电镜扫描部位;

4. 豆粒壳层的假十字波状消光;

5. 壳层内磷灰石的纤柱状微层 (a) 和微粒状微层 (b) 的互层现象, 箭头示微层增长方向;

6. 纤柱状微层的柱状组构 (a) 和微粒微层的粒状组构 (b), 箭头示柱状磷灰石生长方向

并不一样, 即这些颗粒是无序的. 这种微层所占的比重较少, 其单层厚度变化在 $1 \mu \mathrm{m}$ 至 $5 \mu \mathrm{m}$ 之间,有时可以看到它们的分叉和尖灭现象.

在以上所述的核心及其外覆的同心状壳层中没有见到任何微生物遗体或遗迹, 并就其结 构、构造情况来看,它们重分表现出豆粒、䲡粒的基本特点 ${ }^{[4,6]}$

\section{3 豆粒的成因意义}

碳酸盐豆粒、鳁粒曾被广泛深入研究, 并且有各种不同的成因见解 ${ }^{[4,7]}$. 但专门论述磷酸 盐豆粒、鲕粒的文献却很少见. 这种豆粒, 我们推断它是浅水高能海湾中的产物 ${ }^{[3]}$, 所需的基 本条件是海水中具有过饱和的磷酸盐和具有高的活动能量; 前者是物质来源条件, 后者是不可 缺少的环境因素.

从豆粒内核的组分和结构情况可知,它的形成过程相当复杂. 由陆源石英、岩屑和盆内磷 
质、铁质粒屑等组成的内核,经历了各种组分的单独沉积和后来的各种混合或掺合作用. 但内 核的不同成分及其不同组合方式(如单颗石英或多种成分的聚合体)并没有影响其上壳层的沉 积. 这表明磷酸盐壳层和碳酸盐壳层一样,其沉积并不受底质成分的影响,即只要有大于砂级 颗粒的表面积存在就可以导致其沉积 ${ }^{[4]}$.

壳层中的两种组构不同的微层,则是在动荡的富磷海水中以两种不同方式沉积的. 壳内 占优势的纤柱状磷灰石微层, 它均匀完整地覆盖在豆粒表面, 没有见到与其它物体 (特别是海 底)接触而造成的局部缺失现象. 这表明它是豆粒在海水中浮动时沉积的.(图 7-A). 由于大量 晶体在有限的表面积上竞相增长, 造成沿 $c$ 轴迅速生长的磷灰石柱状晶体同轴排列, 即有同一 的消光方向. 这种纤柱状磷灰石微层表明, 在富磷的海水中可以以化学方式直接淀积磷灰石, 而这种方式并不局限于孔隙水内.

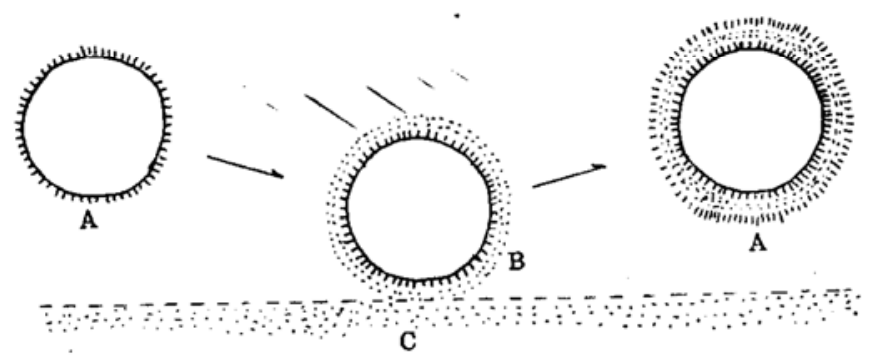

图 7 豆粒壳层成因示意图

$\mathrm{A}$-一豆粒浮动, 淀积纤柱状磷灰石, B-—豆粒滚动, 粘结微粒磷灰石, C一一磷质沉积底质

壳内的微粒状微层是在海水活动减弱、豆粒在底质上滚动时粘结的 (图 7-B). 这种微层中 的微粒光性不一、排列无序, 具有机械沉积特点. 微层本身薄、厚不等并有分叉、尖灭现象, 是 粘结不均和滚动中磨蚀结果. 有的豆粒壳层中甚致夹有由磷质泥晶和硅质粉粒组成的透镜状 微层 ${ }^{[3]}$. 因此推断此类微层为滚动粘结而成.

上已述及,豆粒中没有见到生物遗体. 因而我们推测, 藻对磷的富集 ${ }^{[5]}$ 及其对沉积环境的 改变,可能对豆粒的生成起着间接的重要作用.

致谢感谢叶连俊、张培善、赵大升教授对本文的指导、关怀, 张汝藩高级工程师为本文 提供照片和测试结果.

\section{参考 文献}

[1] 叶连俊等, 华北地台沉积建造, 科学出版社, 1983,37 .

[2] 赵东旭等, 沉积岩石学研究论文集, 科学出版社, $1981,173-190$.

[3] 赵东旭,岩石学报, $1989,(4): 66-71$.

[4] 罗宾、巴瑟斯特著, 中国科学院地质研究所碳酸盐沉积物及其成岩作用翻译组译, 碳酸盐沉积物及其成岩作用. 科学出 版社, $1977,61-65,226-236$.

[5] 刘志礼等,地质学报, $1991,(2): 166-175$.

[6] 地质部地质辞典办公室编, 地质辞典(二), 地质出版社, 1981,192-196.

[7] 华东石油学院岩矿教研室编, 沉积岩石学 (上册), 石油工业出版社, 1982,177--180. 